\title{
Joint Working Group on Quality Assurance in Pathology: Guidance to the professions
}

\author{
D Kilshaw, R Hurley
}

\section{Introduction}

Professional motivation has been central to the conduct of quality assurance programmes throughout the United Kingdom, Europe, and other parts of the world for many years, the single common aim being to effect continuous improvement in the quality of health care.

A general account of the operation of UK NEQAS is given by Lewis and Jennings. ${ }^{1} A$ National External Quality Assessment Scheme (NEQAS) for clinical chemistry in the United Kingdom was introduced in 1969. Since then NEQAS has been extended to encompass most of the pathology disciplines and their subspecialities. Schemes are still experimental in histopathology and cytopathology, but progress is being made towards establishing them definitively from 1993 (UKNEQAS, 1993). ${ }^{2}$ Funding for EQAs in the United Kingdom was provided centrally by health departments until April 1992, but EQAs are now self funding through levies on participants.

In the United Kingdom the Joint Working Group on Quality Assurance in Pathology is charged, on behalf of the professions concerned and through their learned organisations, with the formulation of general guidance to participants in quality assurance schemes and to all who are concerned with quality assurance in pathology. Its constituent membership is drawn from the Association of Clinical Biochemists $(n=1)$, the Association of Clinical Geneticists $(n=1)$, the Association of Clinical Pathologists $(n=2)$, the Association of Medical Microbiologists $(n=1)$, the British Society of Clinical Cytology $(n=1)$, the British Society for Haematology $(n=1)$, the British Society for Immunology $(n=1)$, the Institute of Medical Laboratory Sciences $(n=4)$, the Pathological Society of Great Britain and Ireland $(n=1)$, and the Royal College of Pathologists $(n=4)$. Its members include the chairs of the National Quality Assurance Advisory Panels (NQAAPs) $(n=5)$, and the chair of the former Advisory Committee on the Assessment of Laboratory Standards of the Department of Health. Meetings are attended by an observer from the Department of Health and a director of the board of Clinical Pathology Accreditation UK Ltd (CPA). The group meets twice a year at the headquarters of the main professional associations in rotation. Members report to, and seek counsel from, their parent organisations before the advice of the group is formulated and promulgated.

The Joint Working Group is thus independent of government, and exercises a general coordinating role as professional monitor of existing quality assurance schemes. The detailed operation of this is controlled by steering groups in each discipline. The Joint Working Group has no access to analyses of performance by individual participants, but receives regular reports from the chairs of NQAAPs on the philosophy and operation of national quality assurance schemes. In rare instances the chair of the group may be called to arbitrate between an aggrieved participant and the chair of a panel.

The terms of reference of the Joint Working Group are:

(1) To support and monitor, on behalf of the parent professional bodies and their members, the activity of the advisory panels on quality assurance and particularly their relationships with participant members of the professions, with organisers of relevant UKNEQAS and with other panels;

(2) To comment to organisers of schemes, either through the advisory panels or directly, on the quality of their liaison with advisory panels and participants;

(3) To receive and discuss complaints about quality assurance practices, from members of the pathology professions, which have not been resolved by the steering committees in the disciplines concerned, or by organisers or panels;

(4) To consider suggestions for development of quality assurance schemes, to stimulate and foster any worthy new quality assurance activities within existing or additional areas of laboratory practice, and to indicate to the professions, the appropriate professional body or the Health Departments, the Joint Working Group's views on the need for:

(a) the formulation of further advisory panels on quality assurance in any specialty,

(b) expansion of external quality assessment (EQA) in any field,

(c) modifications to practice of EQAs, 
(d) guidance on general aspects of quality assurance.

(5) To review the composition of the Joint Working Group from time to time as circumstances change and to inform the parent professional organisations of any recommendations for the amendment of its composition.

\section{National Quality Assurance Advisory Panels (NQAAP)}

NQAAPs are professional groups with executive responsibility for the maintenance of satisfactory standards of analytical work in United Kingdom laboratories, whether public or private, in which tests are performed and reported for the detection, diagnosis, or management of disease in man. Their membership composition and terms of reference are determined by the Joint Working Group (Appendix 2). The Association of Clinical Pathologists, the Institute of Medical Laboratory Sciences, the Royal College of Pathologists and certain specialist professional bodies, as approved from time to time by the Joint Working Group, each nominates one member to the panel who normally serves for four years. The chairman of each panel reports to the Joint Working Group.

The panels work closely with the organisers of the UKNEQAS, who bring to their attention laboratories whose performance or frequency of returns are judged unsatisfactory by criteria agreed by the panels with the appropriate steering committee (see below) for the discipline concerned. The annual reports of steering committees are available from scheme organisers.

\section{Steering committees}

Each discipline of pathology with established EQA schemes has a steering committee with a chair. Membership includes appropriate experts and advisors, together with a representative of the Department of Health. A list of scheme organisers and managers, steering committee chairmen, secretaries and members can be found in the yearly reports ${ }^{1}$ formerly published by the Advisory Committee on the Assessment of Laboratory Standards but now to be collated by its successor body.

Steering committees advise organisers on the overall operation of schemes, including the frequency and type of material to be distributed, methods of statistical analysis and

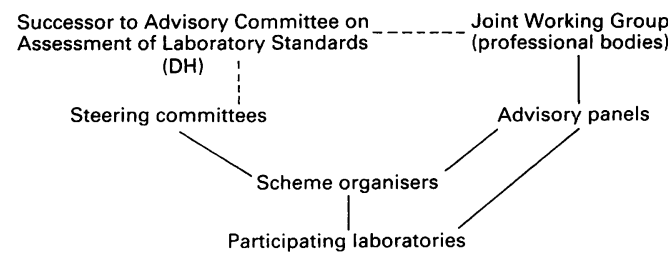

Interaction of quality assessment and assurance committees data presentation, and any extension to the scheme. They receive and discuss comments on the operation of schemes from participants.

Responsibility for ensuring adequate performance of United Kingdom laboratories lies with the panels, who report in general terms to the Joint Working Group. The interaction of the various committees concerned scheme is shown in the figure.

From 1992, all UKNEQAS organisers became members of a consortium appointing five of their number to serve on an executive committee for one year. The executive will oversee the activities of a UKNEQAS office located in Sheffield.

The Joint Working Group is primarily concerned with the issuing of guidance to the professions concerned with the provision of pathology services. Details of the guidance given by the Joint Working Group are contained in the appendices.

\section{Disclosure of participation in NEQAS (Appendix 1)}

In June 1990 revised rules were published by the Joint Working Group for participants in United Kingdom National External Quality Assessment Schemes to take effect from January 1991. The revised rules caused some unrest in many laboratories, because the accompanying letter indicated that although participation in all schemes remained voluntary, the Joint Working Group considered that the fact of participation by individual laboratories, but not details of performance, might properly be disclosed to management and could be obtained from the scheme organisers on request.

\section{Near patient testing (Appendix 3)}

In May 1989 the Joint Working Group issued its guidance document Control of clinical laboratory tests and procedures performed outside the pathology laboratories by non-pathology staff. This reflected its concern over the difficulties of monitoring and ensuring satisfactory standards of performance when diagnostic tests in pathology are performed by non-laboratory staff and those outside the main laboratory.

Near patient testing (NPT) has increased considerably since then, and the guidelines were reviewed and reissued in March 1992, as a more extensive statement was required on the purchase and use of laboratory equipment in non-laboratory environments. Failure to use and maintain equipment correctly can lead to grossly inaccurate results. ${ }^{3}$ There are many advantages to patients and clinical staff in NPT, but to ensure that these are achieved, good quality assurance is essential.

In family practitioner premises NPT has been more widely practised since the introduction of payments for screening in practitioner contracts. The likelihood of more practitioners, and of community pharmacists, investing in diagnostic pathology equipment will increase as a consequence of screening 
for blood glucose, cholesterol, or other analytes, with the corollary that adequate training in methodology and in quality assurance must be made available. Effective liaison between main laboratory and practitioner premises on measurement of blood glucose can be maintained. ${ }^{4}$ Problems relating to specialised equipment have been outlined by Farr. ${ }^{5} \mathrm{~A}$ working party on NPT, comprising representatives from the Royal College of General Practitioners, the Association of Clinical Biochemists, and the Royal College of Pathologists, with observers from the Royal Pharmaceutical Society of Great Britain and the Department of Health, is presently reviewing the provision of bedside diagnostic facilities for general practitioners in comparison with services available in pathology laboratories. The problems of training, quality assurance, expert advice on purchase of appropriate equipment and interpretation of results is being considered. It is hoped that the guidance of the Joint Working Group, already accepted by CPA (UK) Ltd as crucial for purposes of accreditation of laboratories, will be incorporated in the recommendations of the working party.

Meanwhile, NPT is of growing concern to the professions, a concern emphasised by CPA (UK) Ltd. ${ }^{6}$ While recognising that NPT may be of value to the patient, CPA (UK) Ltd expressed anxiety that quality assurance may in some cases be overlooked. CPA (UK) Ltd discussed NPT at a day conference attended by some 200 delegates in April 1993.

\section{Recognition of EQAS as suitable for purposes of laboratory accreditation (Appendix 4)}

Effective participation by laboratories in suitable EQA schemes is regarded by CPA (UK) Ltd as important for the purposes of accreditation. There are many schemes independent of NEQAS which are operated at a regional or local level, or which are available commercially, and some or all of them may be worthy of recognition and approval. At the request of CPA, the Joint Working Group has issued guidance regarding the criteria which, in their professional view, such schemes should satisfy. The Joint Working Group has also agreed to act as the body recognising and approving the professional worth and quality of schemes submitted to it. Clearly, in the event of disagreement between the organisers or sponsors of schemes (the applicants) and the NQAAPs who act on behalf of the Joint Working Group (the assessors) on the quality of such schemes, provision should be made for appeal. This matter is presently being considered by the Joint Working Group.

\section{Future work}

The Joint Working Group will be considering harmonisation of EQAS within the European Community and advising on the establishment of a UKNEQAS board to replace the former Advisory Committee on the Assessment of Laboratory Standards of the Department of Health.

Appendices-copies of these rules can be obtained from D Kilshaw.

Appendix 1: Rules for participation by clinical laboratories in UKNEQAS. Joint Working Group on Quality Assessment. June 1990. Appendix 2: Terms of reference and membership of National Quality Assurance Advisory Panels. Joint Working Group on Quality Assessment. January 1991.

Appendix 3: Guidelines on the control of near-patient testing (NPT) and procedures performed on patients by non-pathology staff. Joint Working Group on Quality Assessment: as revised, March 1993.

Appendix 4: Guidelines on the approval of External Quality Assessment Schemes. Joint Working Group on Quality Assessment. November 1992.

1 Lewis SM, Jennings, RD. United Kingdom External Quality Assessment Schemes. Background and terms of reference. London: Department of Health, 1989.

2 UKNEQAS. UKNEQAS Report and Directory 1993. Sheffield (PO Box 401), 1993.

3 Browning DM, Cowell DC, Kilshaw D, et al. Clinical chemistry equipment outside laboratories. Med Lab Sci 1984;41:99-107.

4 Hope S. Extra laboratory testing and the GP. Connection $1990 ; 22: 2-3$

5 Farr AD. Near-patient laboratory testing. Med Lab Sci 1990;47:249-50.

6 Clinical Pathology Accreditation (UK) Ltd. Bulletin No 3. October 1992, The Children's Hospital, Western Bank, Sheffield. 